\title{
Feasibility study of alternate-day S-1 as adjuvant chemotherapy for gastric cancer: a randomized controlled trial
}

\author{
Shigeru Tatebe $\cdot$ Shunichi Tsujitani $\cdot$ Seiichi Nakamura $\cdot$ \\ Tetsu Shimizu $\cdot$ Nariyuki Yamane $\cdot$ Hideaki Nishidoi $\cdot$ Yasuro Kurisu • \\ Hirotomo Kanayama $\cdot$ Haruaki Ogawa $\cdot$ Masahide Ikeguchi
}

Received: 2 April 2013/Accepted: 28 July 2013/Published online: 15 August 2013

(C) The International Gastric Cancer Association and The Japanese Gastric Cancer Association 2013

\begin{abstract}
Background The Adjuvant Chemotherapy Trial of S-1 for Gastric Cancer established oral S-1 administration for 1 year as the standard postoperative adjuvant chemotherapy for gastric cancer in Japan. We conducted a multicenter cooperative prospective study comparing daily and alternate-day S-1 administration as postoperative adjuvant therapy for gastric cancer.

Methods Patients with Stage II or III gastric cancer who underwent curative surgery were randomly assigned to receive standard daily $\mathrm{S}-1$ administration [group A: 80-120 mg/day S-1 depending on body surface area (BSA); days 1-28 every 6 weeks for 1 year] or alternateday administration (group B: 80-120 mg/day S-1 depending on BSA; alternate days for 15 months). Treatment completion rate was the primary endpoint, and relative dose intensity and safety, overall survival, and relapse-free survival (RFS) were secondary endpoints.
\end{abstract}

For the San-in Clinical Oncology Group.

S. Tatebe $\cdot$ M. Ikeguchi

Division of Surgical Oncology, Department of Surgery,

Faculty of Medicine, Tottori University, 36-1 Nishi-cho,

Yonago, Tottori 683-8504, Japan

S. Tatebe $(\bowtie) \cdot H$. Nishidoi

Department of Surgery, Tottori Red Cross Hospital, 117

Shotoku-cho, Tottori, Tottori 680-8517, Japan

e-mail: tatebe@tottori-med.jrc.or.jp

\section{S. Tsujitani}

National Center for Global Health and Medicine, Tokyo, Japan

S. Nakamura · T. Shimizu

Tottori Prefectural Central Hospital, Tottori, Japan
Results Seventy-three patients were enrolled. The treatment completion rate was $72.2 \%$ in group A and $91.8 \%$ in group B; the relative dose intensity was $67.5 \%$ in group A and $81.2 \%$ in group B; and compliance was better in group B. Digestive system adverse effects were less frequent in group B than in group A. Median follow-up time was 2.8 years; 3-year survival rate was $69.6 \%$ in group A and $87.3 \%$ in group B; and 3-year RFS rate was $76.4 \%$ in group A and $73.1 \%$ in group B.

Conclusions Our data show improved compliance and fewer adverse effects with alternate-day S-1 administration, which appears to be a more sustainable option for adjuvant chemotherapy for Stage II or III gastric cancer.

Keywords Alternate-day S-1 - Gastric cancer . Postoperative adjuvant therapy

\section{Introduction}

$\mathrm{S}-1$ is an oral anticancer agent containing tegafur, gimeracil, and oteracil potassium in a molar ratio of 1:0.4:1 [1].

\author{
N. Yamane \\ Yonago Medical Center, Yonago, Tottori, Japan \\ Y. Kurisu \\ Hamada Medical Center, Hamada, Shimane, Japan \\ H. Kanayama \\ Matsue City Hospital, Matsue, Shimane, Japan \\ H. Ogawa \\ Yasugi Municipal Hospital, Yasugi, Shimane, Japan
}


The response rate to S-1 treatment is approximately $40 \%$ in phase II trials in patients with advanced or recurrent gastric cancer [2, 3]. The Adjuvant Chemotherapy Trial of S-1 for Gastric Cancer (ACTS-GC) trial confirmed that oral S-1 administration for 1 year significantly improved overall survival (OS) and relapse-free survival (RFS) in patients with Stage II or III gastric cancer after curative surgery [4]. The ACTS-GC trial established oral S-1 administration for 1 year as the standard postoperative adjuvant chemotherapy for gastric cancer in Japan. However, the 1-year completion rate was only $65.8 \%$ in the ACTS-GC trial [4]. Therefore, treatment completion remains an unresolved problem.

In clinical practice we observed that alternate-day S-1 administration reduced adverse effects and was tolerable for patients with advanced gastric cancer who were unwilling to continue daily administration. Therefore, we planned a multicenter cooperative prospective randomized phase II study comparing daily with alternate-day S-1 administration as postoperative adjuvant therapy for gastric cancer. The primary endpoint of this study was completion rate, and our aim was to determine whether alternate-day S-1 administration as adjuvant chemotherapy for patients with Stage II and III gastric cancer improved the completion rate of S-1 therapy.

\section{Methods}

\section{Eligibility}

The eligibility criteria were histologically or cytologically proven Stage II, IIIA, or IIIB gastric cancer; D2 or more extensive lymph node dissection at R0 surgery; no hepatic, peritoneal, or distant metastasis; no cancer cells in peritoneal fluid on cytological analysis; age range, 20-80 years; Eastern Cooperative Oncology Group performance status of $0-2$; no previous treatment for cancer except initial gastric resection for a primary lesion; and adequate major organ function before chemotherapy (leukocyte count 3,500-12,000/. $\mathrm{mm}^{3}$; hemoglobin $\geq 9.0 \mathrm{~g} / \mathrm{dl}$; platelet count $\geq 100,000 / \mathrm{mm}^{3}$; total bilirubin $\leq 1.5 \mathrm{mg} / \mathrm{dl}$; aspartate aminotransferase and alanine aminotransferase $\leq 2.5$ times the upper limit of normal; and creatinine $\leq 1.5 \mathrm{mg} / \mathrm{dl}$ ). Stage classification and evaluation of resected specimens were conducted based on the Japanese Gastric Cancer Association guidelines [5].

In the event of toxicity (National Cancer Institute Common Toxicity Criteria: NCI-CTC Version 3.0), the following treatment delays and dose reductions were planned. S-1 administration on day 1 in subsequent cycles was delayed when there was a leukocyte count $<2,000 / \mathrm{mm}^{3}$; neutrophil count $<1,000 / \mathrm{mm}^{3}$; platelet count $<75,000 / \mathrm{mm}^{3}$; hemoglobin $<8.0 \mathrm{~g} / \mathrm{dl}$; aspartate aminotransferase and alanine aminotransferase $>2.5$ times the upper limit of normal; and creatinine $>1.5 \mathrm{mg} / \mathrm{dl}$. S-1 was reduced if any of the following occurred during the previous cycle: febrile neutropenia, platelet count $<50,000 / \mathrm{mm}^{3}$, or grade 3 or higher nonhematological toxicities except nausea, vomiting, anorexia, fatigue, and hypersensitivity. S-1 dose was reduced as follows: $60-50-40 \mathrm{mg}$ twice daily, but the minimum daily dose was $40 \mathrm{mg}$ twice daily. Treatment was continued until disease progression, unacceptable toxicity, patient's refusal, or physician's decision occurred.

\section{Treatment schedule}

Eligible patients were randomly assigned to receive standard daily (group A) or alternate-day (group B) S-1 administration within 6 weeks of surgery (Fig. 1). The treatment schedule is shown in Fig. 1. In both groups, the S-1 dose was based on body surface area (BSA). Patients with a BSA of $\leq 1.25 \mathrm{~m}^{2}$ received $80 \mathrm{mg}$ daily; those with a BSA of $1.25-1.5 \mathrm{~m}^{2}$ received $100 \mathrm{mg}$ daily; and those with a $B S A$ of $\geq 1.5 \mathrm{~m}^{2}$ received $120 \mathrm{mg}$ daily. Patients assigned to group A received $\mathrm{S}-1$ for 28 days every 6 weeks for 12 months, and patients assigned to group B received $\mathrm{S}-1$ on alternate days for 15 months. In both groups, the number of days was equal to the total S-1 administration. Adverse events were evaluated using the NCI-CTC Version 3.0. Written informed consent was obtained from all patients after the institutional review boards of the participating institutions approved the study protocol. This study was conducted in accordance with the Declaration of Helsinki and Good Clinical Practice Guidelines.

\section{Statistical analysis}

The primary endpoint of this study was the completion rate of patients with Stage II and III gastric cancer treated with alternate-day S-1 as adjuvant chemotherapy. In this trial, the rate of treatment completion was expected to be higher than the compliance rate in the ACTS-GC trial because of alternate-day S-1 administration. Assuming a null hypothesis of a $65 \%$ treatment completion rate and an alternative hypothesis of a $85 \%$ treatment completion rate, with one-sided type I error $=0.05$ and type II error $=0.2$, it was necessary to enroll a minimum of 56 patients. Secondary endpoints were relative dose intensity, OS, RFS, and safety. Completion rate was calculated by dividing the number of patients who continued treatment by the total number of patients. Relative dose intensity was defined as the actual dose divided by the planned dose. The OS was defined as the interval from the date of registration to the date of death from any cause or last follow-up. RFS was 
Fig. 1 Study schema and treatment schedule

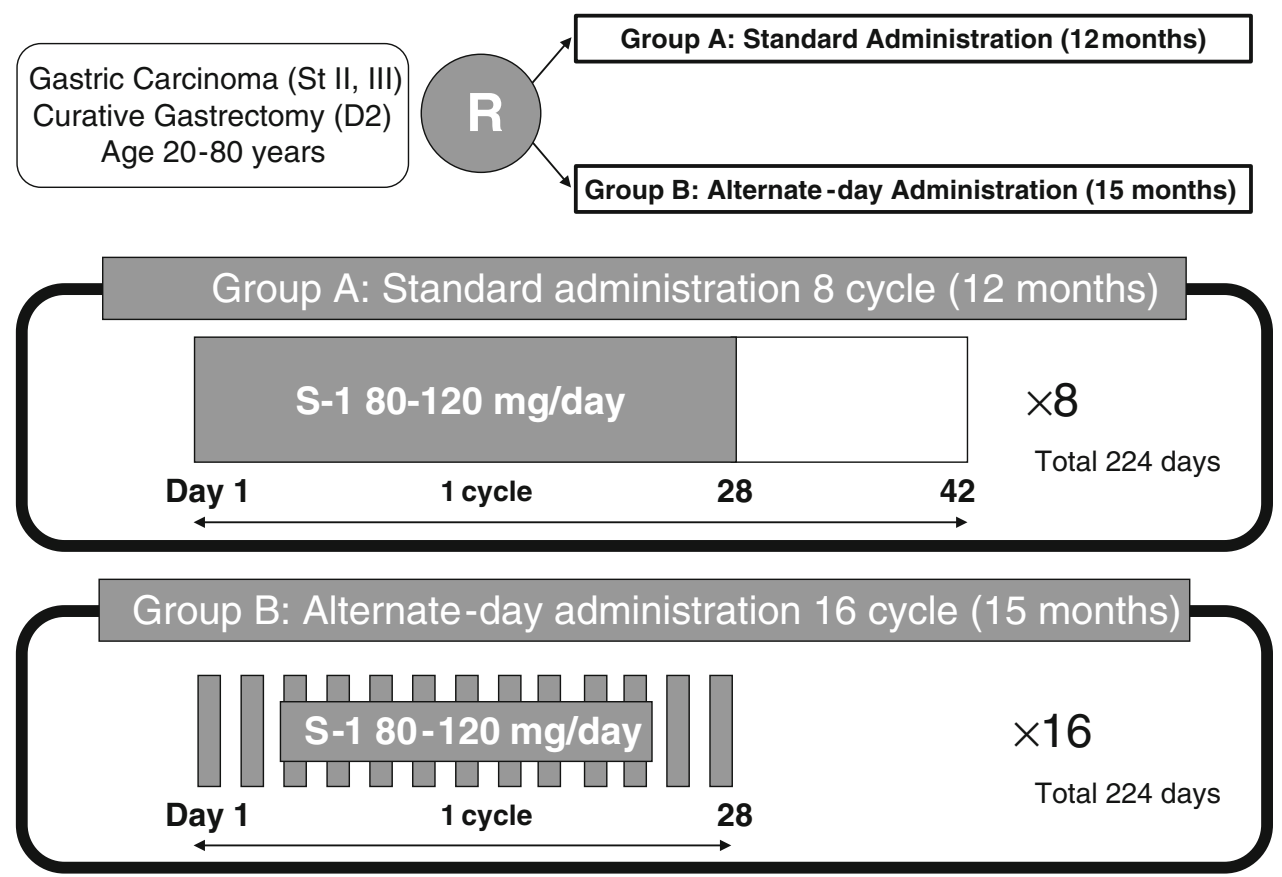

defined as the time from the date of registration to the date when recurrence was confirmed, death from any cause, or last follow-up, whichever came first, and not to the date of treatment discontinuation. Survival curves were estimated using the Kaplan-Meier method, and differences were analyzed using the stratified log-rank test.

\section{Results}

In this study, 73 patients were enrolled between November 2005 and October 2009. Thirty-six patients were randomly allocated into group A and 37 into group B. Patient characteristics are shown in Table 1. All major prognostic factors were similar between the two groups.

Adverse events are shown in Table 2. No difference in the incidence of hematological toxicity was evident between the groups. In addition, no difference in the incidence of nonhematological toxicity above grade 3 was evident between the groups. However, grade 1 or 2 adverse events, including anorexia (53\% vs. $24 \%$ ), nausea ( $28 \%$ vs. $14 \%$ ), and diarrhea ( $33 \%$ vs. $19 \%$ ), were observed more frequently in group A than in group B.

The treatment completion rate was $72.2 \%$ [95\% confidence interval (CI), 54.8-85.8] in group A and $91.8 \%$ (95 \% CI, 78.1-98.3) in group B. Relative dose intensity was $67.5 \%$ in group A and $81.2 \%$ in group B. Treatment completion rate and relative dose intensity improved in group B.

The median time from randomization to follow-up was 2.8 years in both groups. The 3-year RFS rate $(73.0 \%$ in
36 group A patients and $73.1 \%$ in 37 group B patients; $p=0.8505$; Fig. 2) and 3-year OS rate $(69.6 \%$ in group A and $87.3 \%$ in group $\mathrm{B} ; p=0.1954)$ were similar in both groups.

\section{Discussion}

ACTS-GC established oral S-1 administration for 1 year as the standard postoperative adjuvant chemotherapy for gastric cancer in Japan [4]. In the ACTS-GC trial, treatment was continued for at least 3 months in $87.4 \%$, at least 6 months in $77.9 \%$, at least 9 months in $70.8 \%$, and 12 months in $65.8 \%$ of patients. Furthermore, the dose was decreased in $42.9 \%$ of patients receiving S-1. Seventy-one patients $(13.7 \%)$ refused to continue treatment, independent of the investigators, because of adverse events or other factors. Grade 1 or 2 digestive system adverse events, including stomatitis (32\% vs. $3.4 \%$ ), anorexia (55\% vs. $13.7 \%$ ), nausea (35\% vs. $8.9 \%$ ), vomiting ( $21 \%$ vs. $9.1 \%$ ), and diarrhea (57\% vs. $18.3 \%$ ), were more frequent in the S-1 group than in the surgery-only group in the ACTS-GC trial [4]. These results imply that patients will refuse to continue standard S-1 administration because of digestive system adverse events below Grade 2. In a recent study of patients with Stage II or III gastric cancer [6], OS and RFS improved in patients who completed 12 months of adjuvant therapy with S-1 compared with those who discontinued treatment after curative surgery. Furthermore, reduced relative dose intensity is related to 
Table 1 Baseline characteristics of the patients

\begin{tabular}{|c|c|c|}
\hline & $\begin{array}{l}\text { Group A }(n=36) \\
\text { Standard } \\
\text { administration }\end{array}$ & $\begin{array}{l}\text { Group B }(n=37) \\
\text { Alternate-day } \\
\text { administration }\end{array}$ \\
\hline \multicolumn{3}{|l|}{ Age, $n(\%)$} \\
\hline$<60$ years & $8(22 \%)$ & $8(22 \%)$ \\
\hline $60-69$ years & $15(42 \%)$ & $11(30 \%)$ \\
\hline $70-80$ years & $13(36 \%)$ & $18(49 \%)$ \\
\hline Median age, years (range) & $66(45-79)$ & $69(46-80)$ \\
\hline \multicolumn{3}{|l|}{ Gender, $n(\%)$} \\
\hline Male & $26(72 \%)$ & $23(62 \%)$ \\
\hline Female & $10(28 \%)$ & $14(38 \%)$ \\
\hline \multicolumn{3}{|l|}{ Type of gastrectomy, $n(\%)$} \\
\hline Total & $10(28 \%)$ & $14(38 \%)$ \\
\hline Distal & $23(64 \%)$ & $21(57 \%)$ \\
\hline Proximal & $1(3 \%)$ & $0(0 \%)$ \\
\hline Other & $1(3 \%)$ & $2(5 \%)$ \\
\hline Unknown & $1(3 \%)$ & \\
\hline \multicolumn{3}{|c|}{ Depth of tumor invasion, $n(\%)$} \\
\hline pT1 & $1(3 \%)$ & $1(3 \%)$ \\
\hline pT2 & $18(50 \%)$ & $13(35 \%)$ \\
\hline pT3 & $16(44 \%)$ & $20(54 \%)$ \\
\hline pT4 & $0(0 \%)$ & $3(5 \%)$ \\
\hline Unknown & $1(3 \%)$ & \\
\hline \multicolumn{3}{|c|}{ Lymph node metastasis, $n(\%)$} \\
\hline pNO & $4(11 \%)$ & $7(19 \%)$ \\
\hline $\mathrm{pN} 1$ & $18(50 \%)$ & $21(57 \%)$ \\
\hline $\mathrm{pN} 2$ & $13(34 \%)$ & $9(24 \%)$ \\
\hline $\mathrm{pN} 3$ & $0(0 \%)$ & $0(0 \%)$ \\
\hline Unknown & $1(3 \%)$ & \\
\hline \multicolumn{3}{|l|}{ Stage, $n(\%)$} \\
\hline IB & $0(0 \%)$ & $2(5 \%)$ \\
\hline II & $15(40 \%)$ & $13(35 \%)$ \\
\hline IIIA & $17(46 \%)$ & $15(41 \%)$ \\
\hline IIIB & $2(6 \%)$ & $6(14 \%)$ \\
\hline IV & $0(0 \%)$ & $0(0 \%)$ \\
\hline Unknown & $2(6 \%)$ & $1(3 \%)$ \\
\hline
\end{tabular}

decreased disease-free survival in patients with Stage IIIV gastric cancer who underwent curative surgery and received adjuvant S-1 chemotherapy [7]. Reportedly, continued adjuvant chemotherapy after curative surgery is associated with prolonged survival in patients with colon and breast cancers $[8,9]$. Continued S-1 treatment may improve prognosis in patients with gastric cancer after curative surgery. Thus, continued oral S-1 intake is the key to favorable prognoses in patients with advanced gastric cancer after curative surgery.
Differences in cell cycles were observed between cancer and normal cells such as bone marrow or gastrointestinal mucosal cells $[10,11]$. The generation time of normal cells is as short as 0.5-1.5 days, whereas that of cancer cells ranges from 3 to 5 days, and the duration of the S-phase is $\geq 1$ day. Moreover, 5-fluorouracil (5-FU) acts on S-phase cells, inhibits DNA synthesis, and suppresses cell proliferation. Therefore, Shirasaka et al. [12, 13] recommended the use of alternate-day S-1 administration instead of daily use of S-1 based on the observation that the former would allow rescue of normal epithelial cells in the gastrointestinal tract while maintaining the anticancer effect.

Arai et al. [14] demonstrated that alternate-day S-1 administration in patients with gastric cancer reduced adverse events, simultaneously ensuring effective blood levels compared with the standard S-1 administration. In $78 \%$ of patients, the standard S-1 administration was converted to alternate-day administration because of adverse events. After conversion to the alternate-day administration, grade 1 or 2 adverse events, including general fatigue ( $25 \%$ vs. $0 \%$ ), anorexia (19.4\% vs. $0 \%$ ), nausea/vomiting (20.8\% vs. $2.8 \%$ ), and diarrhea (26.4\% vs. $2.8 \%$ ), decreased. Although the trough 5-FU level in patients receiving the alternate-day S-1 administration was significantly lower than in those receiving the standard S-1 administration, the peak effective 5-FU level was reached $2 \mathrm{~h}$ after both alternate-day and standard S-1 administration. In addition, Arai et al. [15] demonstrated that alternate-day S-1 administration was equivalent to consecutiveday administration in terms of relative inhibition of tumor growth, with lower toxicity, in gastric cancer cell lines in vitro and in vivo.

From our small-size randomized phase II study, we found that reducing the dose of S-1 by using the alternateday regimen improved safety and compliance. However, there is no guarantee or evidence that this regimen is significantly more effective than surgery alone.

No significant differences were seen in 3-year OS and RFS rates between group A and group B. In the ACTS-GC trial, the 3-year OS and RFS rates in the S-1 group were $80.1 \%$ and $72.2 \%$, respectively [4]. Survival rates were similar in this study. However, because many of the survival data in this study have been censored, the data must be interpreted with caution.

In conclusion, digestive system adverse events were less frequent with alternate-day than standard S-1 administration. Treatment completion rate and relative dose intensity improved following alternate-day S-1 administration. No significant differences in 3-year OS and RFS rates were evident between group A and group B. Our data indicate that alternate-day S-1 administration may improve com- 
Table 2 Adverse events

\begin{tabular}{|c|c|c|c|c|}
\hline & \multicolumn{2}{|c|}{ Group A $(n=36)$} & \multicolumn{2}{|c|}{ Group B $(n=37)$} \\
\hline & \multicolumn{2}{|c|}{ Standard administration } & \multicolumn{2}{|c|}{ Alternate-day administration } \\
\hline & All & $\geq$ Grade 3 & All & $\geq$ Grade 3 \\
\hline \multicolumn{5}{|l|}{ Hematological toxicity } \\
\hline Leukopenia & $14(39 \%)$ & $1(3 \%)$ & $17(46 \%)$ & $0(0 \%)$ \\
\hline Neutropenia & $12(33 \%)$ & $2(6 \%)$ & $11(30 \%)$ & $2(5 \%)$ \\
\hline Anemia & $14(39 \%)$ & $0(0 \%)$ & $21(57 \%)$ & $0(0 \%)$ \\
\hline Thrombocytopenia & $4(11 \%)$ & $0(0 \%)$ & $4(11 \%)$ & $0(0 \%)$ \\
\hline \multicolumn{5}{|c|}{ Nonhematological toxicity } \\
\hline AST, ALT & $12(33 \%)$ & $1(3 \%)$ & $14(38 \%)$ & $0(0 \%)$ \\
\hline T-Bil & $12(33 \%)$ & $0(0 \%)$ & $6(16 \%)$ & $0(0 \%)$ \\
\hline $\mathrm{Cr}$ & $1(3 \%)$ & $0(0 \%)$ & $3(8 \%)$ & $0(0 \%)$ \\
\hline Anorexia & $19(53 \%)$ & $3(8 \%)$ & $9(24 \%)$ & $3(8 \%)$ \\
\hline Nausea & $10(28 \%)$ & $1(3 \%)$ & $5(14 \%)$ & $1(3 \%)$ \\
\hline Vomiting & $6(17 \%)$ & $0(0 \%)$ & $4(11 \%)$ & $1(3 \%)$ \\
\hline Diarrhea & $12(33 \%)$ & $1(3 \%)$ & $7(19 \%)$ & $0(0 \%)$ \\
\hline Fatigue & $9(25 \%)$ & $0(0 \%)$ & $9(24 \%)$ & $0(0 \%)$ \\
\hline Oral mucositis & $8(22 \%)$ & $2(6 \%)$ & $7(19 \%)$ & $1(3 \%)$ \\
\hline Neuropathy & $4(11 \%)$ & $1(3 \%)$ & $3(8 \%)$ & $1(3 \%)$ \\
\hline
\end{tabular}

$A L T$ alanine aminotransferase, $A S T$ aspartate aminotransferase, $T$-Bil total bilirubin, $C r$ creatinine

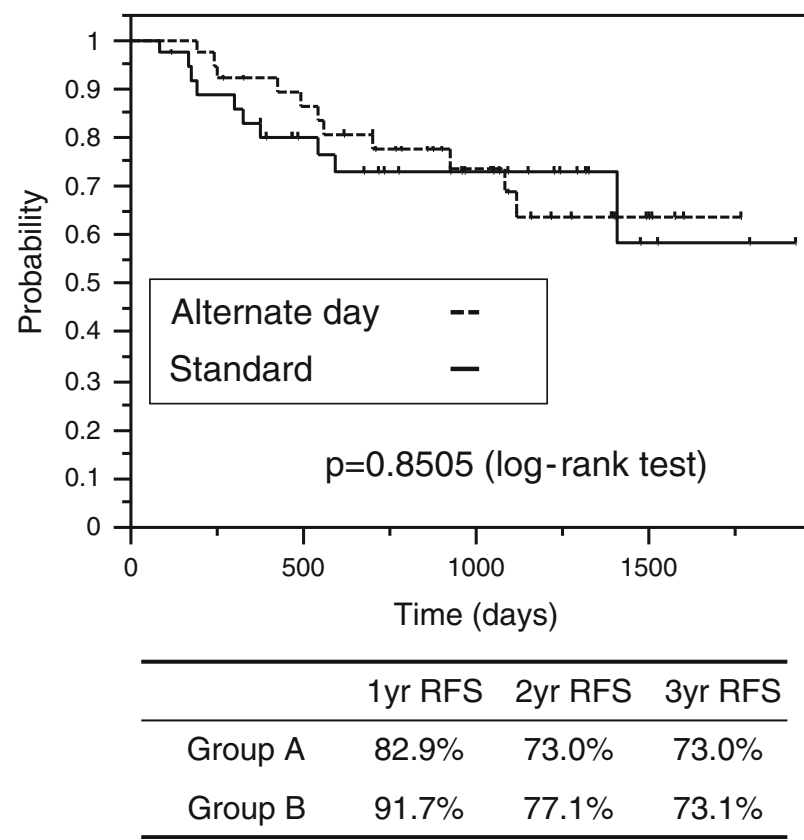

Fig. 2 Kaplan-Meier estimates of relapse-free survival for standard administration and alternate-day administration groups. RFS relapsefree survival

pliance and reduce adverse events in adjuvant S-1 chemotherapy for patients with Stage II or III gastric cancer. The alternate-day S-1 regimen must be confirmed by another large-scale randomized "non-inferiority clinical trial" comparing it to the standard regimen.
Acknowledgments The following are members of the San-in Clinical Oncology Group. Participating Institutions and Principal Investigators: Tottori University Hospital, Tottori (M. Ikeguchi, S. Tsujitani), Tottori Prefectural Central Hospital, Tottori (K. Kishi), Tottori Red Cross Hospital, Tottori (H. Nishidoi), Tottori Seikyo Hospital, Tottori (T. Takeuchi), Sanin Rosai Hospital, Tottori (O. Tanida), Yonago Medical Center, Tottori (O. Kimura), Hakuai Hospital, Tottori (Y. Murata), Nojima Hospital, Tottori (T. Yamamoto), Saihaku Hospital, Tottori (Y. Murata), Hino Hospital (Y. Yamane), Hitachi Memory Hospital, Shimane (K. Arimoto), Yasugi Municipal Hospital, Shimane (H. Ogawa), Matsue City Hospital, Shimane (J. Inoue, M. Miura), Saiseikai Gotsu General Hospital, Shimane (S. Kajitani), Hamada Medical Center, Shimane (Y. Kurisu), Masuda Red Cross Hospital, Shimane (H. Kishimoto), Yoka Hospital, Hyogo (A. Sugesawa), Yashiro Hospital, Hyogo (O. Nishimura).

\section{References}

1. Shirasaka T, Shimamoto Y, Ohshimo H, Yamaguchi M, Kato T, Yonekura K, et al. Development of a novel form of an oral 5-fluorouracil derivative (S-1) directed to the potentiation of the tumor selective cytotoxicity of 5-fluorouracil by two biochemical modulators. Anticancer Drugs. 1996;7:548-57.

2. Sakata Y, Ohtsu A, Horikoshi N, Sugimachi K, Mitachi Y, Taguchi T. Late phase II study of novel oral fluoropyrimidine anticancer drug S-1 (1 M tegafur-0.4 M gimestat-1 M otastat potassium) in advanced gastric cancer patients. Eur $\mathrm{J}$ Cancer. 1998;34:1715-20.

3. Koizumi W, Kurihara M, Nakano S, Hasegawa K. Phase II study of $\mathrm{S}-1$, a novel oral derivative of 5-fluorouracil, in advanced gastric cancer. Oncology. 2000;58:191-7.

4. Sakuramoto S, Sasako M, Yamaguchi T, Kinoshita T, Fujii M, Nashimoto A, et al. Adjuvant chemotherapy for gastric cancer 
with S-1, an oral fluoropyrimidine. N Engl J Med. 2007;357: 1810-20.

5. Japanese Gastric Cancer Association. Japanese classification of gastric carcinoma, 2nd English edition. Gastric Cancer. 1998; $1: 10-24$.

6. Tsujimoto H, Horiguchi H, Hiraki S, Yaguchi Y, Takahata R, Kumano I, et al. Tolerability of adjuvant chemotherapy with S-1 after curative resection in patients with stage II/III gastric cancer. Oncol Lett. 2012;4:1135-9.

7. Kim SJ, Kim YJ, Kim JH, Park do J, Kim HH, Lee JS, et al. Safety, compliance, and predictive parameters for dosage modification in adjuvant S-1 chemotherapy for gastric cancer. Cancer Sci. 2013;104:116-23.

8. Neugut AI, Matasar M, Wang X, McBride R, Jacobson JS, Tsai WY, et al. Duration of adjuvant chemotherapy for colon cancer and survival among the elderly. J Clin Oncol. 2006;24: 2368-75.

9. Bonadonna G, Valagussa P, Moliterni A, Zambetti M, Brambilla C. Adjuvant cyclophosphamide, methotrexate, and fluorouracil in node-positive breast cancer: the results of 20 years of follow-up. N Engl J Med. 1995;332:901-6.
10. Lipkin M, Sherlock P, Bell B. Cell proliferation kinetics in the gastrointestinal tract of man. II. Cell renewal in stomach, ileum, colon, and rectum. Gastroenterology. 1963;45:721-9.

11. Clarkson B, Ota K, Ohkita T, O'Connor A. Kinetics of proliferation of cancer cells in neoplastic effusions in man. Cancer (Phila). 1965;18:1189-213.

12. Shirasaka T, Yamamitsu S, Tsuji A, Taguchi T. Conceptual changes in cancer chemotherapy: from an oral fluoropyrimidine prodrug, UFT, to a novel oral fluoropyrimidine prodrug, S-1, and low-dose FP therapy in Japan. Invest New Drugs. 2000;18:315-29.

13. Shirasaka T. Conceptual changes in cancer chemotherapy-biochemical modulation of 5-FU from bench to clinic. Gan To Kagaku Ryoho 2000;27:193-205 (in Japanese).

14. Arai W, Hosoya Y, Hyodo M, Yokoyama T, Hirashima Y, Yasuda $\mathrm{Y}$, et al. Alternate-day oral therapy with TS-1 for advanced gastric cancer. Int J Clin Oncol. 2004;9:143-8.

15. Arai W, Hosoya Y, Haruta H, Kurashina K, Saito S, Hirashima Y, et al. Comparison of alternate-day versus consecutive-day treatment with S-1: assessment of tumor growth inhibition and toxicity reduction in gastric cancer cell lines in vitro and in vivo. Int J Clin Oncol. 2008;13:515-20. 